better results obtained in the group treated with subcutaneous clacium heparin. The difference in the mean total dose and the kaolin cephalin clotting times between the groups, however, was not significant, and this explanation would therefore seem unlikely. Further doubt is cast on the credibility of this explanation by the findings of Bentley et al, whose results were similar to ours but without differences in the heparin dosage between the two groups.'

Secondly, in comparing our results with those of Hull et al, ${ }^{2}$ Dr Scolding disregards one very important fact. All recurrences in the trial by Hull et al occurred in patients with subtherapeutic anticoagulation, whereas in our study anticoagulation in all patients fell within the therapeutic range, albeit with variations within this range. In a trial such as ours, however, some variation in anticoagulation levels in relation to dosage would seem inevitable.

Thirdly, even if the differences in anticoagulation levels are the explanation the conclusions of our trial are still valid, as subcutaneous administration resulted in a better and more effective therapeutic level than intravenous treatment, without a concomitant increase in complications, haemorrhagic or otherwise.

Thus, finally, the subcutaneous method should still be recommended in preference to the traditional intravenous route.

\section{G WALKER}

J W SHAW

G J L THOMSON

J G R CUMMING

Ninewells Hospital and Medical School Dundee DD1 9SY

M Lea Thomas

St Thomas's Hospital,

London SE1 $7 \mathrm{LH}$

1 Bentley PG, Kakhar VV, Scully MF, et al. An objective study of alternative methods of heparin administration. Thromb Res 1980;18:177-87.

2 Hull RD, Raskob GE, Hirsch J, et al. Continuous intravenous heparin compared with intermittent subcutaneous heparin in the initial treatment of proximal vein thrombosis. $N$ Engl f Med 1986;315:1109-14.

\section{Medical staffing and training in the West Midlands region}

SIR, - We should like to thank Dr D H Vaughan for his comments on our paper (2 May, p 1162). We did note the relation of our working party's figures to regional strategic plans, and we agree that consultant expansion does not seem to be proceeding fast enough to ensure a secure basis for future patient care in the hospital service. Unless the fundamental point continues to be emphasised that in many specialties a higher proportion of patient care should be given by fully trained specialists, the current manpower initiatives wil merely result in a second class service with hopes of continued dependence on overseas doctors, which are very unlikely to be fulfilled. Indeed, by far the best thing for us in the long run would be for doctors from abroad to vote with their feet and stay out of the United Kingdom unless they were individually assured of high quality, well supervised training in the specialties of their choice.

What our figures show is that the reduction in senior house officers and "career" registrars that would be needed to get career progression right in a large region is surprisingly small in mos specialties. In fact, apart from in a few surgical disciplines, keeping the number of senior house officers at its present level would not be unreasonable; it would give scope for broader general clinical training without unjustifiable delay in promotion and would accommudate sume genuine trainees from abruad. At registrar level the figure give a minimum indication of the likely need for "regional" or "career" posts for a modest duration of tenure in the grade. The presence of more experienced registrars who had obtained their higher examinations and would be eligible for some retrospective higher training recognition would increase the registrar numbers above this minimum and would be all the more reasonable as the redistribution of senior registrars will clearly go nowhere near far enough to provide for regional self sufficiency. On top of this there should be a number of overseas trainees occupying registrar posts, so that altogether the total pool of registrar posts in the region might well be quite close to the present number.

For 22 districts the figures in our table indicate enough "career" registrars for them to be spread evenly across the region. Every subspecialty cannot be catered for in this way, and clearly if a royal college or faculty takes the view that a district cannot meet its criteria for training then recognition cannot be given simply so that the safety net rule may be applied. We hope that our article and this letter will suggest that, providing consultant expansion takes place, a practicable way forward is visible in most specialties. For a few specialties, such as trauma and orthopaedics, and accident and emergency, it is difficult to see adequate solutions, and it is here that a thorough reappraisal of the means of providing patient care is most needed.

There are obvious problems to be faced, many of which have been little eased by recent management changes in the National Health Service or the seemingly endless central discussions regarding medical careers. The anxieties and frustrations of those caught up in this situation are, regrettably, not new. They merely intensify, as recent responses to our career surveys show. A little "pump priming" and a little alleviation of the situation in the overcrowded specialties are small steps forward, while most senior house officer and registrar training remains chaotic and districts and regions become increasingly aware of the urgency of sorting out their medical staffing problems.

\section{James Parkhouse \\ DEREK BENNETT} $\mathrm{J} H$ Ross

West Midlands Regional Health Authority, Birmingham B16 9PA

\section{Points}

\section{Explanation and management of neurological disability}

Dr NeIL GoRdon (Booth Hall Children's Hospital, Manchester) writes: Drs E M R Critchley and J D Mitchell (9 May, p 1203) highlight a great need that is rarely met for adults with chronic neurological handicaps. If disabled living centres were set up in every region they would undoubtedly help to integrate the various services that support the disabled. Another group of people, not mentioned in this paper, who would undoubtedly benefit are those who were handicapped in childhood, such as those with cerebral palsy. The provision of assessment and treatment centres for such patients during childhood has greatly improved, as have the facilities for special education and training. When such patients reach adulthood, however, much of the help that has been provided is no longer available. Many will thus be thrown back on the often limited resources of their family, and by then parents, because of their age, will be less able to cope. In spite of the developments in paediatrics there have been no similar ones for older patients, and the call for the establishment of disabled living centres should be considered as a matter of urgency. To begin with, centres for children often had to be started in an unofficial way, with financial support from charitable organisations. Only when their use had been proved were they taken over by the health authorities. Perhaps the same will need to be done by doctors working with disabled adults.

Torsion of the testis: why is the prognosis so poor?

Mr E M KIELY (Hospital for Sick Children, Great Ormond Street, London WCIN 3JH) writes: The article by Drs S Bennett, M S Nicholson, and T M Little (28 March, p 824) draws attention to the poor prognosis associated with testicular torsion. Even estes that seem potentially viable after detorsion are known to have a high risk of subsequent atrophy. Restoration of blood flow to ischaemic tissue results in pronounced swelling and oedema. In the arms and legs this gives rise to the compartment syndrome, and extensive fasciotomy may be necessary to avoid severe ischaemic damage. The tunica albuginea allows limited testicular expansion, and the compartment syndrome may be a consequence of testicular detorsion. Incision of the tunica on the antemesenteric border allows expansion of the testis, and I have not observed postoperative atrophy in testes so treated. Confirmation or otherwise of this idea would be quite straightforward using pressure measurements.

\section{Osteoporosis: cause and management}

Dr B McConkey (Dudley Road Hospital, Birmingham B187QH) writes: Dr J W W Studd et al (18 April p 1032) comment that osteoporosis might be regarded as a connective tissue disorder resulting from a diminution of collagen in the organic matrix. In support of this they comment that osteoporotic patients have thin skin. This is a hypothesis that we advanced in $1963,,^{12}$ suggesting that the relation between osteoporosis and skin change was in a particular appearance of the skin ("transparent skin") rather than just thin skin. We later showed that this clinical appearance was accompanied by recognisable histological characteristics and a diminution in the amoun of collagen. ${ }^{3}$ Subsequently, we also noted dermal connective tissue changes in patients with obstructive airways disease. ${ }^{4}$

McConkey B, Fraser GM, Bligh AS, Whitely $\mathrm{H}$. Transparen kin and osteoporosis. Lancet 1963; 6 :693.

McConkey B, Fraser GM, Bligh AS. Transparent skin and osteoporosis: a study in patients with rheumatoid disease. Ann Rheum Dis 1965:24:219.

3 McConkey B, Walton KW, Carney SA, Lawrence JC, Ricketts CR. Significance of the occurrence of transparent skin.

Ann Rheum Dis 1967;26:219.
4 Smith BS, Williamson N, McConkey B. Dermal connective tissue in patients with chronic obstructive airways disease. Lancet 1967;i:341.

\section{Inappropriate use of confidence intervals}

Dr Peter MacFarlane (Royal Liverpool Children's Hospital, Liverpool L12 2AP) writes: The use of the confidence interval is to be encouraged as a way of presenting clearly the size of differences between groups, ${ }^{1}$ but its use in the paper by Dr P W Soothill and colleagues (25 April, p 1051) was inappropriate and misleading.

Their figure 1 shows the oxygen tensions of growth retarded fetuses and the $95 \%$ confidence interval for normal fetuses. Dr Soothill and coworkers infer that 14 out of 38 growth retarded fetuses had abnormally low oxygen tension by virtue of their position below the "lower limit of the $95 \%$ confidence interval," and this is also referred to by Professor E M Symonds (p 1046). Confidence intervals do not express any normal range or "limit of normality"; they are merely multiples of the standard error of the mean and, as such, express the variability of the sample mean as compared with the true mean of the population. This error of presentation and interpretation does not seem to compromise the main conclusions of the study but should nevertheless not go uncorrected as it appears to be a common misconception.

1 Gardner MJ, Altman DG. Confidence intervals rather than P values: estimation rather than hypothesis testing. $\mathrm{Br}$ Med f 1986;292:746-50. 